[Original article]

\title{
Association between participation in sports club activities and decision-making preferences in end-of-life treatment among Japanese elderly people : a cross-sectional study
}

\author{
Hideaki Kasuga $^{1)}$, Shota Endo ${ }^{1)}$, Yusuke Masuishi ${ }^{1)}$, Tomoo Hidaka ${ }^{1)}$, Takeyasu Kakamu ${ }^{1)}$, \\ Keiko Saito ${ }^{2)}$, Koichi Abe $^{2)}$ and Tetsuhito Fukushima ${ }^{1)}$ \\ ${ }^{1)}$ Department of Hygiene and Preventive Medicine, Fukushima Medical University, Fukushima Prefec- \\ ture, Japan, ${ }^{2)}$ Koriyama City Public Health Center, Fukushima Prefecture, Japan
}

(Received July 28, 2021, accepted October 4, 2021)

\begin{abstract}
Introduction : Decision-making regarding treatment at the end-of-life stage is an important issue for the elderly and their families. Such decision-making may be influenced by activities that promote communication and physical health. The purpose of this study was to examine the association between participation in sports club activities and decision-making regarding life-prolonging treatment among the general community-dwelling Japanese elderly.

Methods : In this cross-sectional study, which used stratified random sampling, 1,603 elderly people aged 65 years or older as of January 2016, living in Fukushima prefecture, Japan were enrolled. Data was collected by a self-completed questionnaire (effective response rate : $53.4 \%$ ). The association of sports club activity participation with a preference for accepting or declining life-prolonging treatment was analyzed by multinomial logistic regression analysis.

Results : Of those participating in sports club activities, the results revealed an odds ratios of 1.812 for participants declining life-prolonging treatment (95\% CI=1.325 to 2.477) and 1.948 for those who preferred life-prolonging treatment $(95 \% \mathrm{CI}=1.160$ to 3.271$)$.

Conclusions : The present study suggests that participation in sports club activities is associated with articulating decisions about life-prolonging treatment in end-of-life care. Consideration of patient involvement in daily activities in non-medical settings may enhance decision-making for endof-life care planning.
\end{abstract}

Key words : Community and Family Medicine, Epidemiology, Health Science, Public Health, Quality of Life

\section{Introduction}

Making end-of-life (EOL) care decisions that respect the wishes of the elderly person in question is associated with increased quality of life (QOL) for both the person and their family. In Japan, elderly people themselves, alongside their families and healthcare professionals get involved in medical decision-making regarding treatment at the EOL stage, whether it be in selecting life-prolonging treatment (LPT) or non-treatment. LPT is defined as all treatment and any interventions that may delay the death of a patient ${ }^{1)}$, whereas non-treatment is a decision to withhold or withdraw potentially $\mathrm{LPTs}^{2}$. The role of healthcare professionals and family members in this context is to support the elderly person at the EOL in making an autonomous decision $^{3)}$.

Many studies have explored key factors in decision-making about care at the EOL stage for the

Corresponding author : Hideaki Kasuga, PhD. E-mail : thidaka@fmu.ac.jp

(C)2021 The Fukushima Society of Medical Science. This article is licensed under a Creative Commons [Attribution-NonCommercial-ShareAlike 4.0 International] license.

https://creativecommons.org/licenses/by-nc-sa/4.0/ 
elderly ; reporting that factors such as age, gender, autonomy in treatment selection, subjective economic status and patient self-efficacy, as well as the presence of a person assisting them in daily life, and their relationship with that person, contributes to the decision-making process ${ }^{4-9}$. However, these previous studies focused on preferences between LPT and non-treatment in elderly people with certain diseases, such as cancer or dementia.

Regarding elderly people in general, previous studies found that clear decision-making about treatment at the EOL stage was associated with frequent communication with family or friends, and with improved physical health status-such as being able to perform activities of daily living ${ }^{10,11}$. A sports club is a place where the formation of social networks and the improvement of one's physical condition are likely to occur ${ }^{12,13)}$. Given that the numbers of elderly people joining local sports/fitness clubs has increased in recent years in Japan, for example in stretching calisthenics and gate ball, ground golf ${ }^{12,14)}$, we hypothesized that participation in sports club activities involving exercise and communication would be associated with enhanced clarification of EOL treatment preferences between LPT and non-treatment.

The purpose of the present study was to examine the association between sports club activity participation and decision-making about LPT among general community-dwelling elderly Japanese. If our hypothesis is confirmed, the results of the current study will provide a basis to further encourage participation in sports club activities for elderly people and indicates the need to support for decision making regarding LPT among those who do not participate in such activities.

\section{Materials and methods}

\section{Study design and sample}

In this cross-sectional study, a stratified random sampling method was used to select 3,000 participants from the population of Koriyama City in Fukushima Prefecture, Japan, as follows. First, of the total elderly population of Koriyama City, those aged 65 years or older, $(84,030 ; 37,382$ males and 46,648 females) who were not receiving nursing care as of November 1, 2016, were selected from the Japanese long-term care insurance system registry and excluded, bringing the number down to 78,821 (33,958 males and 44,863 females).

Next, the potential participants were stratified by gender and location, according to the 20 sub regions outlined by Koriyama City's administrative boundaries. Sampling weights were then applied to adjust for gender and region distributions proportionate to the population size of elderly people. Finally, 1,301 males (43.4\%) and 1,699 females (56.6\%) were enrolled in the study.

In January 2017, we distributed questionnaires to the 3,000 participants, which included items covering basic attributes, participation in sports club activities, and decision-making about treatment at the EOL stage. We also asked if the patient completed the questionnaire themselves and if not, by whom. Participants gave informed consent to participate before taking part. In total, 2,206 participants answered and returned the questionnaires anonymously (response rate $73.5 \%$ ). We excluded questionnaires that were answered by a person other than the participant $(n=373)$, or who incompletely answered $(n=230)$. The number of participants analyzed in the present study was 1,603 in total ; 726 males (45.3\%) and 877 females (54.7\%). The effective response rate was $53.4 \%$. The list of participants in the present study was constructed from the same database of our previous study ${ }^{9}$.

\section{Measures}

\section{Basic attributes}

Basic attributes included age, gender, household composition and subjective economic status. Age was classified into two categories : 65-74 years ('early elderly') and 75 years or older ('late elderly'). Household composition was measured by choosing one of the following items : 'single person', 'couple (age of spouse 65 years or older)', 'couple (age of spouse 64 years or younger)', 'living with one or more sons or daughters', and 'other'. The degree of subjective economic status was assessed using a five-point scale (1, 'very good'; 2, 'good'; 3 , 'fair' ; 4, 'poor' ; and 5 , 'very poor').

\section{Health-related factors}

Subjective health status, subjective happiness, current state/needs of assistance by others in daily life, frequency of participation in sports club activities such as exercise class for the elderly, and current/past health problems were assessed using the following questions, respectively: 'How is your health now?' (four-point scale : 1 , 'very good' ; 2 , 'good' ; 3, 'bad' ; and 4, 'very bad') ; 'How happy are you now?' (11-point scale : 1, 'mostly unhappy'; to 11 , 'mostly happy') ; 'Do you need/receive daily assistance by others? (three-point scale : 1 , 
'neither' ; 2, 'necessary, but do not receive any assistance'; 3 , 'necessary, and received') ; 'Please choose your current/past health problems' (multiple answers allowed : nothing, hypertension, cerebrovascular disease, heart disease, diabetes, dyslipidemia, respiratory disease, gastrointestinal, liver and/ or gallbladder disease, kidney and/or prostate disease, musculoskeletal disease, external injury, cancer, immunological and/or hematological disease, depression, dementia, Parkinson's disease, eye disease, ear/nose/throat disease, and other) ; 'How often do you participate in sports club activities?' (six-point scale : 1, 'over 4 times per week' ; 2 , 'twice or 3 times per week'; 3 , 'once per week'; 4 , 'once to 3 times per month'; 5 , 'a few times per year' ; 6 , 'no participation').

\section{Life-prolonging treatment}

The outcome was the participant's decisionmaking about treatment at the EOL stage, which was measured using the following question: 'Do you prefer LPT at the EOL stage?' (five-point scale : $1=$ 'definitely no', $2=$ 'probably no', $3=$ 'probably yes', $4=$ 'definitely yes', $5=$ 'undetermined'). Many of the previous studies on decision-making at the EOL have focused on whether the person would or would not prefer life-prolonging treatment ${ }^{4-11)}$. However, the decision is not always easy to make, and many elderly people, especially those who are not in imminent danger of death, have not yet decided. Therefore, in this study, we will examine the decision-making of the elderly by three categories: 'prefer', 'would not prefer' and 'undetermined'.

\section{Statistical analysis}

Prior to analysis, household composition was dichotomized: living alone for 'single person' and living with others for 'couple (age of spouse was 65 years or older)', 'couple (age of spouse 64 years or younger)', 'living with one or more sons or daughters', and 'other'. The five degrees of subjective economic status were combined into three categories : poor for 'very poor' and 'poor', fair for 'fair', and good for 'very good' and 'good'. The four degrees of subjective health status were dichotomized : bad for 'very bad' and 'bad', and good for 'very good' and 'good'. As subjective happiness did not have a normal distribution, we set the cutoff at the 25th percentile in order to dichotomize the distribution: a 'high' group included participants with a subjective happiness rating of 7 or higher; and a 'low' group, consisting of participants with a rating of 6 or lower. The three degrees of assistance in daily life were dichotomized: yes for 'necessary, and received' and no for 'neither' or 'necessary, but do not receive any assistance'. The answers to the question of current/past health problems were classified as 0 or $\geq 1$ based on the number of diseases chosen in the question. The six degrees of frequency of participation in sports club activities were dichotomized ${ }^{13)}$ : yes for 'over four times a week', '2 or 3 times a week', 'once a week', ' 1 to 3 times a month', 'a few times a year', and no for 'no participation'. The five degrees of preference for LPT were classified into three categories : not prefer for 'definitely no' and 'probably no', prefer for 'probably yes' and 'definitely yes', and undetermined for 'undetermined'.

Statistical analyses were performed using SPSS statistics version 24 (IBM Corp., Armonk, NY, USA), and the participants' characteristics were summarized using descriptive statistics. The bivariate associations between the above-mentioned factors and outcome variables were examined using a $\chi^{2}$ test, and then the statistical significance of the cells in the tables was analyzed using residual analysis.

Multinomial logistic regression analysis models were prepared to estimate the association between preference for LPT and participation in sports club activities, adjusting for the following potential confounding factors : age, gender, household composition, subjective economic status, subjective health status, subjective happiness, current/past health problems and assistance by others. These were forced entry variables for analysis. Preference for LPT was employed as the dependent variable, setting the individuals who answered "undetermined" as the referent in order to examine whether participation in sports club activities is associated with an articulation of preference between LPT and nontreatment at the EOL stage. The independent variables that were significantly associated with preference for LPT with an odds ratio (OR) higher than 1 were considered to be promoting factors for expressing a clear decision on LPT, while those with ORs lower than 1 were considered to be inhibiting factors.

Variance inflation factor (VIF) was used to test for multicollinearity. The VIF values for age, gender, household composition, subjective economic status, subjective health status, subjective happiness, current/past health problems, need for assistance, and participation in sports club activities were 
$1.072,1.024,1.033,1.139,1.229,1.160,1.058,1.105$, and 1.037, respectively. The mean VIF of the model was less than 6 , showing no collinearity.

$P$ values below 0.05 were regarded as statistically significant. The OR and $95 \%$ confidence interval (CI) were calculated using regression analysis.

\section{Ethics statement}

This study was approved by the Ethics Committee of Fukushima Medical University (Application No. 29,047).

\section{Results}

The characteristics of the participants are shown in Table 1. In total, the mean age of the participants was 74 years (SD : 6.9, range : 65-98), and the numbers of early and late elderly participants were 918 (57.3\%) and 685 (42.7\%) respectively. The most common answers for household composition, subjective economic status, subjective health status, assistance in daily life, current/past health problems, participation in sports club and preference for LPT were 'couple (spouse aged 65 years or older)' (32.4\%), 'fair' (63.1\%), 'good' (70.4\%), 'not need assistance' (85.0\%), 'hypertension' (43.0\%), 'no participation' (78.5\%) and 'definitely no' (45.9\%), respectively. The median score for subjective happiness was 9 .

Bivariate analysis indicated that preference for LPT was significantly associated with age, gender, subjective health status, subjective happiness, assistance in daily life and participation in sports club activities, as shown in Table $2(\phi<0.001,0.004,0.020$, $0.005,<0.001,<0.001$, respectively). Residual analysis revealed that among the participants who participated in sports club activities, the number of those who answered 'undetermined' to the question on LPT was significantly low (13.7\%), whereas the number of those who answered 'not prefer LPT' was significantly high $(24.5 \%)$. No significant associations were found between preference for LPT and other factors.

Results of multinomial logistic regression analysis are shown in Table $3 . \quad$ Compared to the referent, ORs of participants who did not prefer LPT were $0.755(95 \% \mathrm{CI}=0.596,0.957 ; p=0.020)$ for age, $1.339(95 \% \mathrm{CI}=1.024,1.753 ; p=0.033)$ for subjective happiness, $0.183(95 \% \mathrm{CI}=0.112,0.301 ; p$ $<0.001)$ for assistance by others and $1.812(95 \%$ $\mathrm{CI}=1.325,2.477 ; p<0.001)$ for participation in
Table 1. Characteristics $(N=1,603)$

\begin{tabular}{|c|c|c|}
\hline Variables & \multicolumn{2}{|c|}{$n(\%)$} \\
\hline Age $\pm \mathrm{SD}$, years & \multicolumn{2}{|c|}{$74.0 \pm 6.9$} \\
\hline Early elderly & 918 & $(57.3)$ \\
\hline Late elderly & 685 & $(42.7)$ \\
\hline \multicolumn{3}{|l|}{ Gender } \\
\hline Male & 726 & $(45.3)$ \\
\hline Female & 877 & $(54.7)$ \\
\hline \multicolumn{3}{|l|}{ Household composition } \\
\hline Single person & 248 & $(15.5)$ \\
\hline Couple ( $\geq 65$ spouse) & 520 & $(32.4)$ \\
\hline Couple (<65 spouse) & 80 & $(5.0)$ \\
\hline Living with one or more sons or daughters & 519 & $(32.4)$ \\
\hline Others & 236 & $(14.7)$ \\
\hline \multicolumn{3}{|l|}{ Subjective economic status } \\
\hline Very good & 11 & $(0.7)$ \\
\hline Good & 76 & (4.7) \\
\hline Fair & 1,011 & $(63.1)$ \\
\hline Poor & 369 & $(23.0)$ \\
\hline Very poor & 136 & $(8.5)$ \\
\hline \multicolumn{3}{|l|}{ Subjective health status } \\
\hline Very good & 180 & $(11.2)$ \\
\hline Good & 1,128 & $(70.4)$ \\
\hline Bad & 270 & $(16.8)$ \\
\hline Very Bad & 25 & (1.6) \\
\hline Subjective happiness (25-75 percentile) & 9 & $(6-10)$ \\
\hline \multicolumn{3}{|l|}{ Assistance by others in daily life } \\
\hline not need assistance & 1,362 & $(85.0)$ \\
\hline need assistance but don't receive & 149 & $(9.3)$ \\
\hline assisted by others & 92 & (5.7) \\
\hline \multicolumn{3}{|c|}{ Current/past health problems (multiple answers allowed) } \\
\hline Nothing & 218 & $(13.6)$ \\
\hline Hypertension & 689 & $(43.0)$ \\
\hline Cerebrovascular diseases & 64 & $(4.0)$ \\
\hline Heart diseases & 150 & $(9.4)$ \\
\hline Diabetes & 209 & $(13.0)$ \\
\hline Dyslipidemia & 163 & $(10.2)$ \\
\hline Respiratory & 70 & $(4.4)$ \\
\hline Gastrointestinal diseases $\dagger$ & 126 & (7.9) \\
\hline Kidney diseases & 132 & $(8.2)$ \\
\hline Musculoskeletal diseases & 229 & (14.3) \\
\hline External injury & 55 & (3.4) \\
\hline Cancer & 65 & (4.1) \\
\hline Immunological diseases§ & 14 & $(0.9)$ \\
\hline Depression & 14 & $(0.9)$ \\
\hline Dementia & 6 & $(0.4)$ \\
\hline Parkinson's disease & 9 & $(0.6)$ \\
\hline Eye diseases & 362 & $(22.6)$ \\
\hline Ear nose throat diseases & 85 & $(5.3)$ \\
\hline Others & 111 & (6.9) \\
\hline \multicolumn{3}{|l|}{ Participation in sports club } \\
\hline Over 4 times per week & 35 & $(2.2)$ \\
\hline Twice or 3 times per week & 96 & $(6.0)$ \\
\hline Once per week & 65 & (4.1) \\
\hline Once to 3 times per month & 94 & (5.9) \\
\hline Sometimes per year & 55 & (3.4) \\
\hline No participation & 1,258 & $(78.5)$ \\
\hline \multicolumn{3}{|l|}{ Preference for life prolonging treatment } \\
\hline Definitely no & 735 & $(45.9)$ \\
\hline Probably no & 307 & $(19.2)$ \\
\hline Probably yes & 42 & $(2.6)$ \\
\hline Definitely yes & 68 & $(4.2)$ \\
\hline Undetermined & 451 & $(28.1)$ \\
\hline
\end{tabular}

$\dagger$ Gastrointestinal, liver and/or gallbladder diseases.

$\$$ Kidney and/or prostate diseases.

$\S$ Immunological and/or hematological diseases. 
Table 2. Bivariate analysis of the associations of preference for receiving life-prolonging treatment with basic attributes and health-related factor

\begin{tabular}{|c|c|c|c|c|}
\hline \multirow[b]{2}{*}{ Variables } & \multicolumn{3}{|c|}{ Life-prolonging treatment } & \multirow[b]{2}{*}{$p$-value } \\
\hline & Not prefer & Undetermined & Prefer & \\
\hline \multicolumn{5}{|l|}{ Basic attributes } \\
\hline Age, years & & & & $0.004^{*}$ \\
\hline $65-74$ & $628(60.3) \dagger$ & $234(51.9) \ddagger$ & $56(50.9)$ & \\
\hline$\geq 75$ & $414(39.7) \ddagger$ & $217(48.1) \dagger$ & $54(49.1)$ & \\
\hline Gender & & & & $<0.001 *$ \\
\hline Male & $451(43.3) \ddagger$ & $205(45.5)$ & $70(63.6) \dagger$ & \\
\hline Female & $591(56.7) \dagger$ & $246(54.5)$ & $40(36.4) \ddagger$ & \\
\hline Household composition & & & & 0.711 \\
\hline Living alone & $163(15.6)$ & $71(15.7)$ & $14(12.7)$ & \\
\hline Living with others & $879(84.4)$ & $380(84.3)$ & $96(87.3)$ & \\
\hline Subjective economic status & & & & 0.181 \\
\hline Poor & $313(30)$ & $157(34.8)$ & $35(31.8)$ & \\
\hline Fair & $664(63.7)$ & $277(61.4)$ & $70(63.6)$ & \\
\hline Good & $65(6.2)$ & $17(3.8)$ & $5(4.5)$ & \\
\hline \multicolumn{5}{|l|}{ Health-related factors } \\
\hline Subjective health status & & & & $0.020 *$ \\
\hline $\mathrm{Bad}$ & $168(16.1) \ddagger$ & $107(23.7) \dagger$ & $20(18.2)$ & \\
\hline Good & $874(83.9) \dagger$ & $344(76.3) \ddagger$ & $90(81.8)$ & \\
\hline Subjective happiness & & & & $0.005^{*}$ \\
\hline Lower & $255(24.5) \ddagger$ & $146(32.4) \dagger$ & $26(23.6)$ & \\
\hline Higher & $787(75.5) \dagger$ & $305(67.6) \ddagger$ & $84(76.4)$ & \\
\hline Assistance by others in daily life & & & & $<0.001^{*}$ \\
\hline No & $1,015(97.4) \dagger$ & $390(86.5) \ddagger$ & $106(96.4)$ & \\
\hline Yes & $27(2.6) \ddagger$ & $61(13.5) \dagger$ & $4(3.6)$ & \\
\hline Current/past health problems & & & & 0.074 \\
\hline 0 & $156(15)$ & $52(11.5)$ & $10(9.1)$ & \\
\hline$\geq 1$ & $886(85)$ & $399(88.5)$ & $100(90.9)$ & \\
\hline Participation in sports club & & & & $<0.001^{*}$ \\
\hline No & $787(75.5) \ddagger$ & $389(86.3) \dagger$ & $82(74.5)$ & \\
\hline Yes & $255(24.5) \dagger$ & $62(13.7) \ddagger$ & $28(25.5)$ & \\
\hline
\end{tabular}

Note : All categorical variables were examined using a $\chi^{2}$ test.

*Indicates statistical significance.

$\dagger$ Indicates adjusted standardized residual $>1.96$.

$\ddagger$ Indicates adjusted standardized residual $<-1.96$.

sports club activities. Whereas the ORs of participants who preferred LPT were $0.495(95 \% \mathrm{CI}=0.319$, $0.768 ; p=0.002)$ for gender, $0.250(95 \% \mathrm{CI}=0.085$, $0.733 ; p=0.012)$ for assistance by others and 1.948 $(95 \% \mathrm{CI}=1.160,3.271 ; p=0.012)$ for participation in sports club activities.

\section{Discussion}

We conducted the present study in order to examine the association between decision-making about treatment at the EOL stage and participation in sports club activities among the general elderly population in Japan. Consistent with the hypothesis, in the present study, participation in sports club activities was significantly associated with both the desire for and refusal of LPT. Our results suggest that participation in sports club activities is an independent social determinant of decision-making about treatment at the EOL stage.

Participation in sports club activities improves physical health, QOL and self-efficacy through exer- 
Table 3. Logistic-regression analysis for the associations of preference for life prolonging treatment with basic attributes and health-related factors

\begin{tabular}{|c|c|c|c|c|}
\hline \multirow[b]{3}{*}{ Variables } & \multicolumn{4}{|c|}{ Life-prolonging treatment (referent is 'undetermined') } \\
\hline & \multicolumn{2}{|l|}{ Not prefer } & \multicolumn{2}{|l|}{ Prefer } \\
\hline & ORs $(95 \% \mathrm{CI})$ & $p$-value & ORs $(95 \% \mathrm{CI})$ & $p$-value \\
\hline \multicolumn{5}{|l|}{ Factor } \\
\hline Participation in sports club activities (Yes) & $1.812(1.325,2.477)$ & $<0.001 *$ & $1.948(1.160,3.271)$ & $0.012^{*}$ \\
\hline \multicolumn{5}{|l|}{ Confounding Factors } \\
\hline Age (late elderly) & $0.755(0.596,0.957)$ & $0.020 *$ & $\mathrm{~N} / \mathrm{A}$ & \\
\hline Gender (female) & $\mathrm{N} / \mathrm{A}$ & & $0.495(0.319,0.768)$ & $0.002^{*}$ \\
\hline Subjective happiness (High) & $1.339(1.024,1.753)$ & $0.033 *$ & N/A & \\
\hline Assistance by others in daily life (Yes) & $0.183(0.112,0.301)$ & $<0.001^{*}$ & $0.25(0.085,0.733)$ & $0.012^{*}$ \\
\hline Household composition (living with others) & $\mathrm{N} / \mathrm{A}$ & & $\mathrm{N} / \mathrm{A}$ & \\
\hline Subjective economic status (Good) & N/A & & N/A & \\
\hline Subjective health status (Good) & $\mathrm{N} / \mathrm{A}$ & & $\mathrm{N} / \mathrm{A}$ & \\
\hline Current/past health problems $(\geq 1)$ & $\mathrm{N} / \mathrm{A}$ & & $\mathrm{N} / \mathrm{A}$ & \\
\hline
\end{tabular}

N/A means the variable had no significant.

* Indicates statistical significance.

cise, all of which are factors that influence decisions on one's treatment at the EOL stage ${ }^{6,7)}$. For the elderly, it has been suggested that sports clubs function as a place to build connections and exchange opinions and views on health, medical care and the future with other elderly people ${ }^{9,10,15)}$. Participation in sports club activities may have a specific function related to clear decision-making among elderly people.

For factors associated with decisions on LPT other than participation in sports club activities, the present study found that age, being female, receiving assistance in daily life and subjective happiness were also associated with such decisions. First, age worked as an inhibiting factor for the refusal of LPT but was not associated with decisions on LPT ; this suggests that elderly peoples' decisionmaking becomes unclear as they age, which is consistent with past studies that have reported that elderly people tend to leave EOL decisions to someone else, and their decisions tend to change as they advance in age and as their conditions deteriorate $^{5,16,17)}$. Although the need for decision-making in EOL care increases with aging as death becomes more realistic, decision-making may not be enhanced by aging.

Next, being female was found to be an inhibiting factor in the desire for LPT in the present study. This is consistent with previous studies, which reported that women are less likely to seek $\mathrm{LPT}^{18-20)}$; females want their husbands to receive LPT and live longer, while they do not want $t^{20)}$.
On the other hand, no significant difference in gender was found in the answers 'not prefer LPT' or 'undetermined' in the present study. These results indicate that gender may not contribute to the promotion of decision-making.

Third, receiving assistance in daily life was found to be an inhibiting factor in the desire for and refusal of LPT. These results may be explained by the reduction of subjectivity in treatment participation among elderly people receiving assistance ; they may tend to leave such decisions to caregivers as their symptoms worsen and self-efficacy and autonomy decline ${ }^{10)}$. A more detailed examination of the environment and psychological state of care recipients is required.

Finally, high subjective happiness was found to be a promoting factor for refusal of LPT, coinciding with previous studies ${ }^{21-23)}$. Those studies indicated that low subjective happiness was associated with psychological problems such as depression and anxiety $^{20,21}$, and these psychological problems were reported to be associated with procrastination tenden$\mathrm{cy}^{14,23,24)}$. It is thought that high subjective happiness might prevent procrastination in decisionmaking regarding EOL treatment ${ }^{14)}$.

Importantly, clarification of the decision-making process by elderly people about EOL treatment can contribute to elderly person-centered care, with respect to their preference and reduce the burden on surrogate decision makers. Many previous studies of LPT decisions have focused on patients with certain diseases, hospital residents, and surrogate deci- 
sion makers and have examined the impact of patients' relationships with healthcare professionals on clear decision-making on treatment in medical settings. In the current study, we found that participation in sports club activities, as a part of daily activities in non-medical settings, promotes clear decision-making about treatment preferences at the EOL stage.

This study has four limitations. First, the participants of this study were selected from a single city in Japan ; future research should have more representative populations sampled from more areas than in the current study. Second, we did not investigate how the preferences for LPT are linked to actual treatment decisions at the EOL stage. A longitudinal study is needed to clarify this limitation. Third, in this study, the presence or absence of current/past health problems was used in the analysis, but the kind of symptoms were not examined, therefore it is important to conduct analyses that take this into account. Fourth, it should be noted that this study used an independently developed scale for health-related factors and preference for LPT, so its validity needs to be confirmed in future studies.

In conclusion, the present study revealed that participation in sports club activities was associated with clear decision-making about the EOL, whether to receive or refuse LPT, whereas aging, gender, and daily assistance by others inhibited such decisions. It is important to create an environment that would help elderly people consider their EOL treatment options and make decisions, providing a clear guide for those who have difficulty in making such decisions. To provide effective support for the elderly, gerontologists and public health experts should consider patient background regarding participation in sports club activities.

\section{Study Funding}

This research received no specific grant from any funding agency.

\section{Disclosure}

The authors declare that there are no conflicts of interest.

\section{References}

1. Norwegian Directorate of Health. Decision-making processes in the limitation of life-prolonging treatment,
https://helsedirektoratet.no/Lists/Publikasjoner/ Attachments/67/IS-2091-Beslutningsprosesser-vedbegrensning-av-livsforlengende-behandling.pdf. [Accessed 11 July 2021].

2. van der Heide A, Deliens L, Faisst K, et al. Endof-life decision-making in six European countries : descriptive study. Lancet, 362 : 345-350, 2003.

3. Shanley C, Fetherstonhaugh D, McAuliffe L, Bauer M, Beattie E. Providing support to surrogate decision-makers for people living with dementia : Healthcare professional, organisational and community responsibilities. Health Soc Care Community, 25 : 1563-1570, 2017.

4. Martins Pereira S, Fradique E, Hernández-Marrero P. End-of-Life Decision Making in Palliative Care and Recommendations of the Council of Europe : Qualitative Secondary Analysis of Interviews and Observation Field Notes. J Palliat Med, 21: 604-605, 2018.

5. Kwak J, Haley WE. Current Research Findings on End-of-Life Decision Making Among Racially or Ethnically Diverse Groups. Gerontologist, 45 : 634-641, 2005.

6. Haidet P, Hamel MB, Davis RB, et al. Outcomes, preferences for resuscitation, and physician-patient communication among patients with metastatic colorectal cancer: SUPPORT Investigators. Study to Understand Prognoses and Preferences for Outcomes and Risks of Treatments. Am J Med, 105 : 222-229, 1998.

7. Phillips RS, Wenger NS, Teno J, et al. Choices of seriously ill patients about cardiopulmonary resuscitation : correlates and outcomes. SUPPORT Investigators. Study to Understand Prognoses and Preferences for Outcomes and Risks of Treatments. Am J Med, 100 : 128-137, 1996.

8. Nilsson ME, Maciejewski PK, Zhang B, et al. Mental health, treatment preferences, advance care planning, location, and quality of death in advanced cancer patients with dependent children. Cancer, 115 : 399-409, 2009.

9. Hidaka T, Endo S, Kasuga H, et al. Disparity in pre-emptive end-of-life conversation experience caused by subjective economic status among general Japanese elderly people : a cross-sectional study with stratified random sampling. BMJ Open, 9(10) : e031681, 2019.

10. Winter L, Parker B. Current health and preferences for life-prolonging treatments : An application of prospect theory to end-of-life decision making. Soc Sci Med, 65 : 1695-1707, 2007.

11. Lambert AS, Elton J. Contradictions and Promise for End-of-Life Communication among Family and Friends : Death over Dinner Conversations. Behav Sci (Basel), 7 : E24, 2017. 
12. Tomioka K, Kurumatani N, Hosoi H. Positive and negative influences of social participation on physical and mental health among community-dwelling elderly aged 65-70 years : a cross-sectional study in Japan. BMC Geriatr, 19 ; 17(1) : 111, 2017.

13. Schmidt A, Jung J, Ernstmann N, et al. The association between active participation in a sports club, physical activity and social network on the development of lung cancer in smokers : a casecontrol study. BMC Res Notes, 5 : 2, 2012.

14. Ministry of Economy, Trade and Industry of Japan. Analysis of All Industrial Activities: The Fourth Quarter of 2014 (Review of the year 2014), (in Japanese) https://www.meti.go.jp/statistics/toppage/ report/bunseki/pdf/h26/h4a1502j.pdf. [Accessed July 11 2021].

15. Silveira MJ, Kim SYH, Langa KM. Advance directives and outcomes of surrogate decision making before death. N Engl J Med, 362 : 1211-1218, 2010.

16. Hirakawa Y, Chiang C, Hilawe EH, Aoyama A. Content of advance care planning among Japanese elderly people living at home : A qualitative study. Arch Gerontol Geriatr, 70 : 162-168, 2017.

17. Caillet P, Canoui-Poitrine F, Vouriot J, et al. Comprehensive geriatric assessment in the decisionmaking process in elderly patients with cancer : ELCAPA study. J Clin Oncol, 29 : 3636-
3642, 2011.

18. Phillips RS, Wenger NS, Teno J, et al. Choices of seriously ill patients about cardiopulmonary resuscitation : correlates and outcomes. SUPPORT Investigators. Study to Understand Prognoses and Preferences for Outcomes and Risks of Treatments. Am J Med, 100 : 128-137, 1996.

19. Seale C, Ziebland S, Charteris-Black J. Gender, cancer experience and internet use : A comparative keyword analysis of interviews and online cancer support groups. Soc Sci Med, 62 : 25772590, 2006.

20. Arbera S, Vandrevalab T, Daly T, Hampson S. Understanding gender differences in older people's attitudes towards life-prolonging medical technologies. J Aging Stud, 22 : 366-375, 2008.

21. Spinhoven P, Elzinga BM, Giltay E, Penninx BWJH. Anxious or depressed and still happy? PLoS One, 10 : e0139912, 2015.

22. Schiffrin HH, Nelson SK. Stressed and happy? Investigating the relationship between Happiness and perceived stress. J Happiness Stud, 11 : 33$39,2010$.

23. Solomon LJ, Rothblum ED. Academic procrastination : frequency and cognitive-behavioral correlates. J Couns Psychol, 31 : 503-509, 1984.

24. Lay CH. At last, my research article on procrastination. J Res Pers, 20 : 474-495, 1986. 